\title{
TEACHERS' PERSPICACITY ON THE IMPLEMENTATION OF SNOEZELEN ROOM FOR EMOTIONAL THERAPY OF AUTISTIC CHILDREN
}

\author{
Fadzidah Abdullah ${ }^{1 *}$, Mohd Hisyamuddin Kassim², \\ Arita Hanim Awang ${ }^{3}$, Mohd Hizam Hussain ${ }^{4}$, Mohd Raziff Abd. Razak ${ }^{5}$
${ }^{2}$ Mr., Multimedia University Malaysia, MALAYSIA, mhisyamk@gmail.com
${ }^{3}$ Asst.Prof. Dr., International Islamic University Malaysia, MALAYSIA, aritahanim@iium.edu.my
${ }^{4} \mathrm{Mr}$., Hashim Awang Primary School, MALAYSIA.
${ }^{5}$ Mr., University Kuala Lumpur British Malaysian Institute, MALAYSIA, mraziff@unikl.edu.my
${ }^{*}$ Corresponding Author \\ ${ }^{1}$ Assoc. Prof. Dr., International Islamic University Malaysia, MALAYSIA, fadzidah@iium.edu.my
}

\begin{abstract}
United Nations Sustainable Development Goals (2016-2030) has the initiative to transform the education system through out the globe, to develop holistic individuals. For autistic children, holistic development should address the autistic children's needs of emotional therapy as well. This research has the objective to examine teachers' perspicacity on the implementation of Snoezelen Room for the emotional therapy of children with autism. In Malaysia, a Snoezelen Room was built at Hashim Awang Primary School to provide not only an interactive learning facility, but also to support the emotional therapy of autistic children. The research uses both the qualitative and quantitative approaches. The secondary data is collected via table research, to review the circumstantial situation surrounding the development of Snoezelen room. Meanwhile, for the primary data collection, a survey questionnaire is distributed to teachers who involved directly with the teachers' training program and implementation of the Snoezelen Room at the school. Those teachers have had special training to handle and teach children with autism. The collected survey data is then studied empirically by using statistical analysis approach, to generate intrinsic findings and conclusion. The quantitative analysis is divided into three parts which are demography of the respondents, Snoezelen Room preparation and Snoezelen Room implementation. All participated teachers gave positive feedback towards the implementation. They agreed that having a snoezelen room in the proximity of inclusive schools in Malaysia is deemed necessary to support the Malaysian national agenda of holistic educational approach. Hence, it is hoped that the Malaysian Education Ministry will establish more inclusive schools with the provision of Snoezelen rooms for holistic development of children with autism.
\end{abstract}

Keywords: Emotional Therapy, Autistic Children, Interactive Learning, Sensory Environment, Holistic Development, Inclusive Design, Inclusive School.

\section{INTRODUCTION}

Malaysia supports United Nations Sustainable Development Goals (2016-2030), to provide inclusiveness of public schools; equal opportunity and unbiased opportunity for education; and promotion of lifelong learning for all. Hence, the initiatives anticipate transforming the education system to develop holistic individuals. For 
autistic children, holistic development should address the autistic children's needs of emotional therapy as well. Thence, a Snoezelen Room has been built at Hashim Awang Primary School to provide not only an interactive learning facility for autistic children, but also to support their emotional therapy too. The Snoezelen Room serves as the first showcase application of interactive learning environment in Malaysia, for the emotional therapy of children with autism. The room is equipped with both ICT hard-ware and software, to produce a multi-sensory environment for the autistic children to learning while playing. Upon the implementation of Snoezelen Room in the school, teachers are trained to master the usage of related equipment and to lead the process of teaching the autistic children. Accordingly, this research examines teachers' perspicacity on the implementation of the Snoezelen Room for the emotional therapy of children with autism.

\section{BACKGROUND STUDY}

Children with autism were used to be considered as beyond any possible improvement and cure. The only option for them was to be institutionalised. However, recent research showed that early diagnosis and appropriate intervention could result to incredible difference in their life. Hence, Malaysian government has adapted the inclusiveness framework in national educational system, where children with autism are placed in the main-stream schools. This effort is consistent with the United Nations Convention of on the Rights of Persons with Disabilities (CRPD) and its Optional Protocol, which states that regular schools with inclusive orientation are the most effective means of combating discriminatory attitudes, creating welcoming communities, building an inclusive society and achieving education for all (Fina and Cera, 2015).

Nevertheless, perceiving one policy could fit all is deceptive to the well-being of autistic children. The inclusive education does not address the autistic children's wide-ranging needs for special learning environment which will enhance their performance. Children with autism need not only access to autismfriendly learning environment, but also therapeutic environment for their emotional therapy. Hence, besides the need to be treated equally like normal pupils, children with autism in the main-stream schools need therapeutic environment for their emotional therapy.

Similarly, the special education system (Mohd. Nor, 2007) provides access to children with a learning disability to the mainstream education. Moreover, while policies and standards for People with Disabilities (PWD), such as MS 1184, MS 1331, MS 1183, have served to encourage building codes that ensure physical access to and within public settings for people with disability, but have done little to ensure access for intellectually disabled persons. Thus, these policies and standards do not address the requirements of a large spectrum of sensory and cognitive disabilities. Therefore, children with cognitive disabilities like autism often stay out of the picture.

\subsection{Definition of Autism}

Autism is a developmental disability that significantly affects a person's ability to communicate both verbally and nonverbally, which simultaneously affects the person's capability to socially interact with the community. This condition is usually manifested at young age, when care takers realise the children's incapability to perform in the normal learning process. Autistic children also have the potential to engage in repetitive activities, partake in stereotyped movements, resist to environmental changes, and response strangely to sensory experiences (American Psychiatric Association APA, 2000). Other characteristics often associated with autism are engaging in repetitive activities and stereotyped movements, resistance to environmental change or change in daily routines, and unusual responses to sensory experiences (American Psychiatric Association APA, 2000).

Autism falls into the category of learning disabilities. There is no current data available on the prevalence rate of autism in Malaysia. However, Kassim, Othman, Guat and Yusoff (2009) mentioned that prevalence of autism in Malaysia was 1.6 per 1000 among children aged 18th months to 3 years in 2006. They also mentioned that annually a total of 1500-1800 new cases of disabilities were diagnosed among children less than 7 years and more than $50 \%$ of them were intellectually challenged. In 2015, Joanna Menon Lim reported that data indicates that in the United State alone, the prevalence of autism is as high as 1 in 68 children. Hence, she projected that Malaysia also has an upward trend in autism prevalence (Lim, 2015).

\subsection{Design Approaches for Autism Treatment Centers and Educational Spaces}

Present design methods for autism treatment centres concentrate either on skill development which is known as Sensory Design Theory (Mostafa, 2014) or rigid adaptation to day-to-day circumstances known as NeuroTypical Approach (Henry, 2011). In accordance with treatment plans, the two major design approaches have been created, both based on the perception issues of people with autism, and also possessing features 
almost opposite to one another (Pomana, 2014). In order to design a therapeutic environment related to autism spectrum, the initial understanding on the current theory about Sensory Integration and relation between Autism and Sensory environment is a must. Sadek (2016) highlights that analysis of various spatial measures will provide and facilitate accurate descriptions of spatial layout for the special educational spaces.

\subsubsection{Sensory Integration and Sensory Environment}

Autistic children frequently have difficulties with sensory integration which are the senses that are experienced through sight, touch, sound, taste and smell (Denise, 2011). Sensory integration is the organizing of all the information that comes in from the senses. Sensory integration is a child-directed, sensory enriched therapy that depends upon a specialized environment. The specialized environment for sensory integration is called sensory environment. This specially designed environment induces children to be playful and fun, while being active and flexible. Most therapists consider the specialized environment to be both an art and a science (Herbert, 2002).

The design of sensory environment is often bounded in a room; hence, scholars often use the term Snoezelen Room rather than sensory environment. The word 'snoezelen' is a combination of two Dutch words, meaning 'sniffing' and 'dozing,' and the word refers to the "pleasurable sensory experiences generated in an atmosphere of trust and relaxation" (Kwok, et.al. 2003). Meanwhile, sensory processing refers to human ability to gather information using the five senses, organise the gathered information, and then interpret the information to make a meaningful response (Rudy, 2008).

\subsubsection{Autism and Sensory Environment}

The key to designing for autistic children seems to revolve around the sensory environment and its relationship to autistic behaviour (Lewis, 2017). As autistic behaviour might be the result of a malfunction in sensory perception; hence, providing an environment with sensory atmosphere will encourage the autistic children to use their five senses. However, their brain malfunction may take the form of hypersensitivity or hypo-sensitivity, leaving them with an altered perception to touch, sound, smell, light, colour, and texture (Mostafa, 2014). Therefore, when designing areas for children on the autism spectrum, it is important to have knowledge and understanding of how they experience the environment, the people, and the objects within the environment (Scott, 2011). In fact, sensory environment could further assist on behaviour and perception development of the autistic children too.

\subsection{Two approaches for Autism Treatment Centers and Educational Spaces}

There are two (2) approaches known to be implemented for the Autism Treatment Centres and Educational Spaces. The first approach is Neuro-Typical Design, which is centred on direct integration to different typical urban and public situations. According to Mostafa (2014), this approach recommends the immersion of the autistic users to a stimulating environment, which replicates the level of stimulation found in the real world. The Neuro-Typical Design offers high stimulus environment, focused on adapting to environment, but inadequate for severe autism. Implementation of this approach is relevant for a long-term therapy of autistic users who have limited skill development, and underestimates autistic sensory deficiencies (Pomana, 2014).

The second approach is Sensory Design Theory, which stipulates that favourably altering the sensory environment (Mostafa, 2014), particularly for educational setting. This approach focuses on creating a controlled sensory environment that makes autistic people feel comfortable, therefore facilitating skill acquirement. Sensory Design Approach offers Low stimulus environment, adaptable to severe autism and focused on skill acquirement. It may limit integration for less severe cases and requires more effort and welltrained therapists but insufficient for real world situations (Pomana, 2014).

\subsection{Therapeutic Learning Environment for Emotional Therapy of Autistic Children}

The sensory room, which is also called "snoezelen" room, is the first emotional therapy room concept developed in the Netherlands (Hosny \& Anous, 2015). The word Soneselen is derived from the blending of two Dutch verbs: "snuffelen," which means to seek out or explore, and "doezelen," which means to relax. The room was initially developed by two Dutch therapists in the 1970s and was designed to provide a soothing and stimulating environment for institutionalized patients with dementia and profound developmental disorders by delivering stimuli to various senses, using lighting effects, colour, sounds, music, and scent (Kwok et al, 2003).

Over the years, Snoezelen rooms have been developed throughout the world. This facility could help children with autism and other disabilities to better regulate the amount of sensory stimulation they experience. The room is usually filled with special equipment and tools such as a vibrating platform, 
speakers, an LED projector, a motorized mirror ball, beanbag chairs and bubble tubes, all of which be adjusted by the children to meet their needs. The activities provided in a sensory intervention (SI) room may benefit autistic children in becoming more physically active or accepting a wider range of sensory experiences when used as part of a comprehensive intervention program. As the American Academy of Paediatrics (AAP) Council on Children with Disabilities states that sensory activities may help to calm the autistic children and reinforce their desired behaviour.

In Malaysia, there is very limited research in the use of multi-sensory environments (Snoezelen/ sensory rooms) for children with Autistic Spectrum Disorder (ASD). Sensory intervention theory and specific effects of sensory intervention based therapies are lacking supporting evidence from well-designed studies. Developing a new framework for emotional therapy room which can be adopted in Malaysia public school is a vital start. This framework should include the planning and training of teachers who would participate in the program. Hence, examining teachers' perspicacity on the implementation of the first Snoezelen Room in Malaysia could contribute to the success of the national mission of having successful inclusive schools that caters for the benefit of children with autism.

\section{RESEARCH METHODOLOGY}

The main method of data collections for this research is via distribution of survey questionnaires to teachers who involved directly with the training program and implementation of the Snoezelen Room at the school. The teachers have had special training to handle and teach children with autism. The collected survey data is then studied empirically by using statistical analysis approach, to generate intrinsic findings and conclusion. Secondary data is collected via table research, to review the circumstantial situation surrounding the development of Snoezelen room.

\subsection{Strategy and Analysis}

The analysis is divided into three parts which are demography of the respondents, Snoezelen Room preparation and Snoezelen Room implementation. The first part consists of the study on the demography of expert respondents which covers the post, gender, and age. The second part related to the Snoezelen Room preparation. The questionnaire survey consists of three set of questions; (V1) Should your school develop Snoezelen Room?, (V2) Are the materials for the Snoezelen Room available at your school?, and (V3) Does the cost of developing the Snoezelen Room under school budget?

The third part related to the 'Snoezelen Room' implementation. This part consists of three set of questions; (V4) Does the Snoezelen Room offers emotional therapy to students while experiencing 'Tantrum,' (V5) Does the Snoezelen Room atmosphere in line with the 'multi-sensory' requirements, and (V6) Does the Snoezelen room is easy to use? The research also seeks to investigate the significant level of relationship between the preparation and implementation stage of the Snoezelen Room.

\section{RESULTS AND DISCUSSION}

\subsection{Demography of Respondents}

The questionnaire survey was distributed at Hashim Awang Primary School (Sekolah Kebangsaan), Kepala Batas, Pulau Pinang, Malaysia. Table 1 shows the demography of the respondents. The total number of respondents participated in the survey were 17 teachers. Among the respondents, $76.5 \%$ were female, $11.8 \%$ were male, and the rest did not state their gender. There were only two post categories involved in the fields survey. There were grade 41 to 44 category, $82.4 \%$ and grade 27 to 40 category, $17.6 \%$. Referring to the age, the highest percentage of respondents were between 36 to 45 years old category, which is $58.8 \%$, followed by between 26 to 35 years old category at $35.3 \%$ and 46 to 55 years old category at $5.9 \%$.

Table 1 Demography of Respondents

\begin{tabular}{|c|c|c|c|c|c|c|}
\hline \multicolumn{2}{|c|}{ Gender } & \multicolumn{2}{c|}{ Post } & \multicolumn{3}{c|}{ Age } \\
\hline Male & Female & $\begin{array}{c}\text { Grade } 41 \text { to } \\
44\end{array}$ & $\begin{array}{c}\text { Grade } 27 \text { to } \\
40\end{array}$ & $\begin{array}{c}46-55 \text { Years } \\
\text { Old }\end{array}$ & $\begin{array}{c}36-45 \text { Years } \\
\text { Old }\end{array}$ & $\begin{array}{c}26-35 \text { Years } \\
\text { Old }\end{array}$ \\
\hline $11.8 \%$ & $76.5 \%$ & $82.4 \%$ & $17.6 \%$ & $5.9 \%$ & $58.8 \%$ & $35.3 \%$ \\
\hline
\end{tabular}




\subsection{Snoezelen Room Preparation}

As shown in Table 2, the one-sample t-test (test value $=3$ ) is conducted to determine the significance level of the Snoezelen Room preparation. There were three set of questions involved in the questionnaire V1, V2, and $\mathrm{V} 3$.

Table 2 One-Sample Test

\begin{tabular}{|c|c|c|c|c|c|c|}
\hline \multirow{3}{*}{ Questions A } & \multicolumn{6}{|c|}{ Test Value $=3$} \\
\hline & \multirow{2}{*}{$\mathrm{t}$} & \multirow{2}{*}{$\mathrm{df}$} & \multirow{2}{*}{ Sig. (2-tailed) } & \multirow{2}{*}{$\begin{array}{c}\text { Mean } \\
\text { Difference }\end{array}$} & \multicolumn{2}{|c|}{$\begin{array}{l}\text { 95\% Confidence Interval of the } \\
\text { Difference }\end{array}$} \\
\hline & & & & & Lower & Upper \\
\hline V1 & 5.470 & 16 & .000 & 1.412 & .86 & 1.96 \\
\hline V2 & 3.395 & 16 & .004 & .647 & .24 & 1.05 \\
\hline V3 & .324 & 16 & .750 & .059 & -.33 & .44 \\
\hline
\end{tabular}

Overall, the Snoezelen Room preparation score was statistically higher than normal Snoezelen Room preparation score (test value $=3$ ). There was statistically significant reported on $\mathrm{V} 1 \mathrm{t}(16)=5.470, p=.000$, followed by $\mathrm{V} 2 \mathrm{t}(16)=3.395, \mathrm{p}=.004$. However, there was statistically no significant reported on $\mathrm{V} 3 \mathrm{t}(16)=$ $.324, p=.324$ where the Snoezelen Room development was not under the school budget. In summary, the expert respondents believed that the Snoezelen Room should be developed at the school as a part of teaching and learning facility for the students with autism. Furthermore, the availability of required materials for the teaching and learning purposes in the Snoezelen Room was easy to find.

\subsection{Snoezelen Room Implementation}

Analysis is also conducted using the one-sample t-test (test value $=3$ ) to determine the significance level of the Snoezelen Room implementation. Table 3 shows the One-Sample Test of Snoezelen Room Implementation. There were three set of questions involved in the questionnaire, V4, V5, and V6.

Table 3 One-Sample Test of Snoezelen Room Implementation

\begin{tabular}{|l|c|c|c|c|c|c|}
\hline & \multicolumn{3}{|c|}{ Test Value $=3$} \\
\cline { 5 - 7 } & \multirow{2}{*}{ Question B } & & $\mathrm{df}$ & Sig. (2-tailed) & Mean Difference & \multicolumn{2}{|c|}{ 95\% Confidence Interval of the Difference } \\
\cline { 5 - 7 } & & & & & Lower & Upper \\
\hline V4 & 5.098 & 16 & .000 & 1.294 & .76 & 1.83 \\
\hline V5 & 7.098 & 16 & .000 & 1.353 & .95 & 1.76 \\
\hline V6 & 7.778 & 16 & .000 & 1.294 & .94 & 1.65 \\
\hline
\end{tabular}

Overall, the Snoezelen Room implementation score was statistically higher than normal Snoezelen Room implementation score (test value $=3$ ). There was statistically significant reported on V6 $t(16)=7.778, p=$ .000 , followed by V5 $\mathrm{t}(16)=7.098, \mathrm{p}=.004$. The lowest score reported on $\mathrm{V} 4 \mathrm{t}(16)=5.098, \mathrm{p}=.000$. In summary, the respondents believed that the Snoezelen Room was user-friendly and capable of generating emotional therapy via a multi-sensory of teaching and learning environment.

\subsection{The Relationship between Preparation and Implementation}

The research seeks to investigate the significant level of relationship between the preparation and implementation of the Snoezelen Room. Table 4 shows the relationship between the preparation and implementation of the Snoezelen Room. 
Table 4 The Relationship between Preparation and Implementation

\begin{tabular}{|l|l|c|c|c|}
\hline $\begin{array}{l}\text { Preparation and } \\
\text { Implementation }\end{array}$ & & $\mathrm{V} 4$ & $\mathrm{~V} 5$ & $\mathrm{~V} 6$ \\
\hline \multirow{4}{*}{ V1 } & Pearson Correlation & $.838^{* *}$ & $.787^{* *}$ & $.680^{* *}$ \\
\cline { 2 - 5 } & Sig. (2-tailed) & .000 & .000 & .003 \\
\cline { 2 - 5 } & $\mathrm{N}$ & 17 & 17 & 17 \\
\hline \multirow{3}{*}{ V2 } & Pearson Correlation & $.514^{*}$ & .417 & .205 \\
\cline { 2 - 5 } & Sig. (2-tailed) & .035 & .096 & .431 \\
\cline { 2 - 5 } & N & 17 & 17 & 17 \\
\hline \multirow{2}{*}{ V3 } & Pearson Correlation & -.103 & -.038 & -.036 \\
\cline { 2 - 5 } & Sig. (2-tailed) & .693 & .886 & .891 \\
\cline { 2 - 5 } & N & 17 & 17 & 17 \\
\hline
\end{tabular}

*. Correlation is significant at the 0.05 level (2-tailed).

${ }^{* *}$. Correlation is significant at the 0.01 level (2-tailed).

There were significant correlations between the preparation and implementation of Snoezelen Room, $<p=$ 0.05 and $<p=0.01$. In this case of $<p=0.01$, there was a perfect, positive correlation between V1 and V4, $r=.838, N=16, p<.001$, followed by a strong, positive correlation between $V 1$ and $V 5, r=.787, N=16, p<$ .001 and $V 6, r=.680, N=16, p<.001$. The respondents believed that the Snoezelen Room should be developed as a part of a teaching and learning facility as the room capable of generating emotional therapy via a multi-sensory environment while having 'Tantrum.'. In the case of $<p=0.05$, there was a moderate, positive correlation between $\mathrm{V} 2$ and $\mathrm{V} 4, \mathrm{r}=.514, \mathrm{~N}=16, \mathrm{p}<.005$. The rest of the questions showed no significant correlations between preparation and implementation. Thus, the respondent agreed that the Snoezelen Room was user-friendly and the teaching and learning content was easily available for the students with autism.

\section{CONCLUSION}

This study has the intention to examines teachers' perspicacity on the implementation of the Snoezelen Room for the emotional therapy of children with autism. This study concludes that teachers who involved in the preparation of Snoezelen Room believed that the sensory room should be developed in inclusive schools because the required materials are readily available in schools, and the cost of developing the Snoezelen room is affordable. The expert respondents also believed that the Snoezelen Room should be developed at the school as a part of teaching and learning facility for the students with autism. Furthermore, the availability of required materials for the teaching and learning purposes in the Snoezelen Room was easy to find.

In term of the implementation of Snoezelen Room at the school, the respondents believed that the school's Snoezelen room had successfully offered emotional therapy for autistic children, provided the right atmosphere of a sensory environment, and could be used at ease. Hence, having a snoezelen room in the proximity of inclusive schools in Malaysia is deemed necessary to support the national agenda of holistic educational approach. It is hoped that the Malaysian government could continue to support such endeavour so that the emotional therapy of autistic children could be nurtured together with the process of educating them. 


\section{REFERENCE LIST}

American Psychiatric Association, (2000). Pervasive developmental disorders, diagnostic and statistical manual of mental disorders, fourth edition-text revision (DSM-IV-TR). Washington DC: Author.

Denise,T., (2011). Color \& Autism: Seeing Color through Autistic Children's Eyes, Available online at http://colorturners.blogspot.com/2011/03/color-autism.html

Hebert, B., (2002). Design Guidelines of a Therapeutic Garden for Autistic Children", MLA thesis dissertation, Department of Landscape Architecture, Louisiana State University.

Joanna Menon Lim,(2015). Living with Autism in Malaysia. Policy Idea No 21. IDEAS, Institute of Democracy and Economic Affairs.

Fina V. D., and Cera, R., (2015). Protecting the Rights of People with Autism in the Fields of Education and Employment International, European and National Perspectives. London and New York: Springer International Publishing.

Henry, C, (2018). Designing for Autism, the Neuro-Typical Approach", ArchDaily, available online at: http://www.archdaily.com/181402/designing-for-autism-the-neuro-typical-approach

Inas Hosny Ibrahim Anous, (2015). The impact of Interior Design in educational spaces for children with Autism" American International Journal of Research in Humanities, Arts and Social Sciences.

Kassim, A. B., Othman, S., Guat, L. P., \& Yusoff, Z., (2009). Country Report Malaysia, Paper presented at 7th ASEAN \& JAPAN High Level Official Meeting on Caring Societies, Tokyo. Retrieved February 1, 2011, from http://www.scribd.com/doc/42941627/Malaysia-Country-Report.

Kwok, H., To, Y., \& Sung, H., (2003). The application of a multisensory Snoezelen room for people with learning disabilities - Hong Kong experience. Hong Kong Medical Journal, 9:122-6.

Lewis, U. A., (2017). Designing Schools for Students on the Spectrum. The Design Journal, 20:sup1, S2215S2229, DOI: 10.1080/14606925.2017.1352738

Sadek, A. H., (2016). Space Syntax Analysis: Tools for Augmenting the Precision of Healthcare Facility. HERD-HEALTH ENV RES, 9 (4).

Mohd. Nor Bin Mohamad Taib, (2007). School management concerning collaboration with social resources in the community- its approaches and problems. Paper presented in the 27th Asia-Pacific International Seminar on Education for Individuals with Special Needs organized by National Institute of Special Needs Education, Japanese National Commission for UNESCO, Yokohama.

Mostafa, M. (2014). Architecture for Autism: Autism ASPECTSS TM in School Design. Archnet-IJAR: International Journal of Architectural Research, vol. 8, issue 1,pp.143-158.

Mostafa ,M, (2014). An Architecture for Autism, Towards More Inclusive Built Environments for Individuals with Autism Spectrum Disorders", United Nations, Geneva, 11th Session of the CRPD, April, 2014.

Pomana, A, (2014). Architectural Design for Autism , Treatment centers destined to people with autistic spectrum disorders" dissertation,UAUIM Bucuresti.

Rudy , L, J., (2018). Sensory Integration, Sensory Processing Disorder and Autism ", available online at http://autism.about.com/od/treatmentoptions/a/whatisspd.html

Scott, I. , (2011). Designing learning spaces for children on the autism spectrum", Good Autism Practice 10(1): 36-51. 